\title{
Adsorption/Desorption Studies of Peanut Husks Using Salicylic Acid Model
}

\author{
Gudovan Dragos ${ }^{1}$, Gudovan Iulia Alexandra ${ }^{1,2}$, Ivanof Ana ${ }^{3}$, Stefanov Maria Georgiana ${ }^{3}$ \\ ${ }^{1}$ University Politehnica from Bucharest, Faculty of Applied Chemistry and Materials Science, Department of Organic \\ Chemistry "C. Nenitescu", Polizu Str. 1-7, Bucharest, Romania \\ ${ }^{2}$ National Institute of Endocrinology "C.I. Parhon”, Blvd. Aviatorilor 34-36, Bucharest, Romania \\ ${ }^{3}$ University Politehnica from Bucharest, Faculty of Medical Engineering, Polizu Str. 1-7, Bucharest, Romania \\ dragosgudovan@gmail.com; iuliagudovan@gmail.com
}

\section{Extended Abstract}

Peanut husks have been investigated during the last few years in the struggle to improve the options in the department of environmental pollution by using natural materials which have the main advantages of being highly biodegradable [1] and coming from a renewable source. Environmental pollution can follow two main strategies, one being organic compounds depollution [2] and the other coming from inorganic mixtures, mainly heavy metal ions [3][4][5][6]. The aim of the present study is to test the sorption properties of unmodified peanut husks, the only operation made on the peanut husks being the milling in a laboratory mill. The effect of the temperature treatment on the sorption behaviour of the resulting peanut husks powder was tested. We chose to test the peanut husks powder due to the ease of filling, in some applications where a filled column is required the whole peanut husks being much more difficult to manage. For the characterisation of the powder SEM (Scanning electron microscopy), HPLC (high pressure liquid chromatography), FT_IR (Fourrier transformed infrared spectroscopy) and CNSH elemental analysis (carbon-nitrogen-sulphur-hydrogen) were used. The results are promising and the desorption properties could indicate a possible delivery vessel for controlled drug delivery, although more tests are required to entertain this theory.

\section{References}

[1] C. S. Wu, "Utilization of peanut husks as a filler in aliphatic-aromatic polyesters: Preparation, characterization, and biodegradability," Polymer Degradation and Stability, vol. 97, no. 11, pp. 2388-2395, 2012.

[2] I. Safarik and M. Safarikova, "Magnetic fluid modified peanut husks as an adsorbent for organic dyes removal," Physics Procedia, vol. 9, pp. 274-278, 2010.

[3] S. Ricordel, S. Taha, I. Cisse, and G. Dorange, "Heavy metals removal by adsorption onto peanut husks carbon: characterization, kinetic study and modelling," Separation and Purification Technology, vol. 24, no. 3, pp. 389-401.

[4] S. Taha, S. Ricordel, and I. Cisse, "Kinetic study and modelling of heavy metals removal by adsorption onto peanut husks incinerated residues," Energy Procedia, vol. 6, pp. 143-152, 2011.

[5] Q. Cheng, Q. Huang, S. Khan, Y. Liu, Z. Liao, G. Li, and Y. S. Ok, "Adsorption of Cd by peanut husks and peanut husk biochar from aqueous solutions," Ecological Engineering, vol. 87, pp. 240-245, 2016.

[6] L. Rozumova, O. Zivotsky, J. Seidlerova, O. Motyka, I. Safarik, and M. Safarikova, "Magnetically modified peanut husks as an effective sorbent of heavy metals," Journal of Environmental Chemical Engineering, vol. 4, no. 1, pp. 549-555, 2016. 